David Becerra Mayor

Universidad Autónoma de Madrid

\title{
BODAS DE SANGRE: LA TRAGEDIA MODERNA Y LA PROBLEMÁTICA DEL YO
}

La figura de Federico García Lorca ha sido harto estudiada y por eso podemos afirmar, sin reparo alguno, que lo sabemos todo (o casi todo) acerca de la vida y la obra del poeta de Fuente Vaqueros. Sin embargo, conviene señalar también que la imagen que de Lorca se ha incorporado a nuestra tradición literaria no ha sido sino una construcción simbólica cuya sombra en ocasiones obnubila su propia realidad histórica. Lorca aparece casi siempre convertido en «el símbolo inequívoco del asesinato de un pueblo inocente e inerme» (Rodríguez, 1994: 11) y las aproximaciones críticas que se han hecho sobre su obra suelen construirse sobre las cenizas de esa derrota.

La obra de García Lorca, por consiguiente, es recibida con absoluta complacencia y leída frecuentemente con una anulación total del sentido crítico. Y esto es así porque Lorca acostumbra a ser leído como un héroe -en tanto que víctima- de la Guerra Civil española y a menudo sus lecturas se erigen a partir de los hechos que acaecieron en Viznar el 19 de agosto de 1936. También sus detractores, como es el caso de Jorge Luis Borges -que al parecer arremetía contra el poeta granadino porque no supo entender una broma que le gastó éste en Buenos Aires-, pretende derrumbar el mito a partir de los mismos hechos acontecidos en la fecha señalada, al asegurar que el fusilamiento de Federico García Lorca había favorecido su fama. La sacralización del poeta constituye un lastre para su profunda investigación

Lo que se pretende en estas páginas es un estudio de Lorca -en concreto, de una de sus obras: Bodas de sangre- sin la necesidad del mito, sino de su costado inverso, esto es, la Historia. Pues resulta imprescindible para un acercamiento real a la obra de Federico García Lorca, situar al autor en sus específicas coordenadas históricas, aquéllas que determinan, en última instancia, el funcionamiento objetivo del texto. Es decir, se propone aquí el análisis del texto literario como el resultado de los mecanismos de producción de la coyuntura histórica en que dicho fenómeno se inscribe. Sin desdeñar, por supuesto, las contradicciones históricas -latentes de forma clara en el tiempo de Lorca- y la acumulación de un excedente ideológico que reacciona desde la supraestructura contra el funcionamiento objetivo de base. Esto es lo que Juan Carlos Rodríguez ha denominado la «objetividad del texto», que postula lo que sigue: «la lógica interna de cada inconsciente ideológico no puede ser si no es anterior a su propio proceso histórico de producción» (Rodríguez, 1994: 10). De lo que se trata, pues, citando de nuevo a Juan Carlos Rodríguez, es de

[...] averiguar en Lorca algo más adentro, esa cuestión clave del sentido en tanto que objetividad, lo que bulle (o brilla o serpea) entre el significado y la verdad, su límite: el espesor inconsciente que trama lo literario, el trazado de cada línea poética o de cada realización escénica. Lo único, pues, que importa: no la realización sujeto/objeto (que implica siempre una idealidad subjetiva fenomenológica) sino la objetividad del texto al margen de tal relación (Rodríguez, 1994: 10).

Pues bien, la objetividad del texto, su sentido, no puede sino encontrarse en la objetividad de la época. Porque, como señala José Ortega, «el hombre Lorca, como ser his- 
tórico, crea un arte que se inscribe en una superestructura ideológica y que está inevitablemente relacionado con su período histórico» (Ortega, 1989: 10). Habrá de apuntarse, aunque sea de forma breve, que la coyuntura histórica en que Lorca se inscribe está marcada por la contradicción entre el desarrollo económico capitalista, que domina las relaciones sociales y económicas de la infraestructura, y la reacción pequeño-burguesa que, si bien no ejerce control sobre el funcionamiento objetivo de base, sí mantiene su poder sobre los AIE (Aparatos Ideológicos de Estado) y reacciona ante la consolidación del capitalismo desde la supraestructura política. (Habrá que señalarse, de igual modo, que posteriormente, cuando la consolidación del capitalismo ofrezca su posición más liberal, surgirá una nueva confrontación social con una nueva clase que no será sino el proletariado).

El capitalismo -sus relaciones sociales, sus modos de producción, etc.- introduce en el horizonte epistemológico y social nuevas categorías contra las cuales habrá de reaccionar la supraestructura pequeño-burguesa con tal de mantener su status político. Todas ellas derivarán de la matriz ideológica básica de la burguesía: la propiedad privada. La invención de la propiedad privada, que a nivel económico supone la transformación de los bienes inmuebles en bienes muebles (esto es, la propiedad en mercancía y por consiguiente en capital), en el plano existencial, conlleva la aparición de categorías que sólo pudieron emerger del inconsciente ideológico burgués: el yo, la individualidad, la voluntad, el deseo, etc. Desde la noción burguesa del yo se cuestiona el orden social establecido y por ello, desde la supraestructura, se reacciona contra dichas categorías con tal de recuperar la templanza inicial. Esta contradicción es la base de la tragedia moderna, latente en la producción dramática populista de Federico García Lorca y, en concreto, en Bodas de sangre.

En 1941, Mijail Bajtín escribía un artículo titulado «Épica y novela (acerca de la metodología del análisis novelístico)» ${ }^{1}$ (Bajtín, 1989: 449-485) con el que establecía las diferencias fundamentales entre el universo literario de la epopeya clásica y la novela moderna. La diferencia estriba para Bajtín en que los espacios de la épica son siempre perfectos y cerrados, inalterables e inaccesibles a la experiencia personal. La tragedia se genera en este universo perfecto, en el que el héroe no puede sino someterse a un destino previa-mente escrito: «El héroe épico y el trágico no son nada al margen de su destino y del argumento supeditado a éste» (Bajtín, 1989: 481). La muerte del Dios nietzscheano pone fin a la tragedia en tanto que el héroe ya no debe someterse a su destino, sino que se le presenta ante sus ojos un universo abierto, racional y en construcción. Sin embargo esto no imposibilita la producción trágica de Lorca:

Los problemas aristotélicos y teóricos que tanto exasperaban a los dramaturgos ingleses, franceses y alemanes no suponían para Lorca un legado indispensable ni una barrera para la creación de la tragedia, puesto que él, a través de su propio duende y su propia «cultura de sangre», podía beber de la misma fuente que los antiguos «griegos misteriosos»; y la cultura popular en España -máxime en Andalucía- no había padecido el yugo del racionalismo excesivo que convertiría la lógica en una religión secular, conversión que significaría el triunfo de la clase media y del melodrama burgués, pero que al mismo tiempo mataría el antiguo sentido fatalista de la verdadera tragedia (JosephsCaballero, 2005: 22).

\footnotetext{
${ }^{1}$ Vid., igualmente, Geörgy Lukács (1970: 29-39 y 59-72).
} 
La presencia de lo irracional en el seno de la Andalucía trascendental, efectivamente, tiene su correlación con la tragedia clásica, cuyo desenlace no quedaba nunca sujeto a las leyes materiales. Este hecho favorece que Bodas de sangre, en su composición formal, guarde ciertas similitudes con la tragedia griega. La idea de la repetición, del retorno, se introduce en Lorca con el fin de mostrar la unicidad entre la vida y la muerte, entendiendo ésta como el nuevo punto de origen. Esta vuelta al mundo unitario y cerrado se produce en Bodas de sangre a partir de los presagios y el círculo temporal en torno a los tres años (tiempo que le duró el marido a la Madre; tres años atrás finalizó la relación amorosa entre la Novia y Leonardo, etc.). Como afirma Luis Fernández Cifuentes, «el destino de la familia es la repetición» y «desde el primer momento, la comunicación entre los personajes no tendrá otro objeto que recordar o prevenir una relación familiar, recordar o prevenir su ruptura» (Fernández Cifuentes, 1986: 147). La forma trágica es posible debido a las características del campo andaluz:

A consecuencia del conservadurismo radical del campo andaluz y de numerosos factores sociohistóricos -entre ellos la invasión musulmana, la marginación del campo andaluz por parte de los conquistadores castellanos, y el estancamiento de todo el país después del colapso del imperio español- la vieja vida mediterránea del sur de España, muy parecida a la que había dado luz a la tragedia griega, se había «congelado» mientras el mundo occidental experimentaba grandes revoluciones industriales, científicas, políticas y religiosas (Fernández Cifuentes, 1986: 17).

El conservadurismo del campo andaluz no es una cuestión endémica ni trascendental, inherente a la propia tierra, sino que responde a la situación económica donde la tradición latifundista detiene el desarrollo de la economía capitalista en un permanente estadio de acumulación primitiva de capital, que beneficia a la pequeña-burguesía rural. Para mantener su posición de clase, la pequeña-burguesía no puede sino mostrar su carácter refractario frente al desarrollo capitalista de base. Por ello se opone a todas sus manifestaciones ideológicas, como son el deseo o la libertad individual. Y es esta reacción supraestructural, que impide la noción de libertad, lo que permite que exista la tragedia como posibilidad literaria. Porque la tragedia lorquiana no responde sino a la problemática de un yo que no puede constituirse, reafirmarse, en tanto que sujeto libre, debido a la autoridad -moral, política, ideológica- que se lo impide. Es decir, como señala Juan Carlos Rodríguez, «no hablemos ya de lo trágico como latencia de muerte, sino [...] de lo trágico como imposibilidad histórica de nombrarse, sentirse «individualizado» (Rodríguez, 2002: 499). O lo que es lo mismo: «El problema de la individualización está en el origen de la tragedia moderna» (Rodríguez, 2002: 500). Esta problemática -la problemática del yo- recorre la obra dramática populista ${ }^{2}$ de Federico García Lorca y, en concreto, Bodas de sangre.

De entrada, Bodas de sangre nos presenta, desde el mismo dramatis personae, a una serie de personajes que carecen de nombre propio. Los personajes, como afirma Fernández Cifuentes, son definidos «por las relaciones familiares y su ruptura: no constituyen individualidades sino nudos de una red familiar» (Fernández Cifuentes, 1986: 147). Desde el mismo programa en el que se encuentra la relación de los personajes que habrán de aparecer

${ }^{2}$ Nos referimos a populista en el mejor sentido de la palabra, refiriéndonos a las obras de evidente perfil didáctico y que muestran un interés claro de acercar la cultura al pueblo y cuya producción coincide con la proclamación de la II República y el teatro de La Barraca. 
en la obra, Lorca se está inscribiendo en la tragedia moderna, en su imposibilidad de construir individuos con nombre propio. Los personajes no se construyen como sujetos autónomos, sino como entes sin identidad encadenados a la estructura de la familia. No es casualidad, por lo tanto, que el único personaje con nombre propio sea Leonardo, quien desencadenará la ruptura del orden, quien introducirá el conflicto, y quien, consiguientemente, provocará el fatal desenlace. Leonardo tiene nombre porque es el único personaje que, con el propósito de realizar sus deseos, se enfrenta al orden establecido; su individualidad se reafirma por medio de sus acciones y de su voluntad. Y sus deseos no serán otros que impedir la boda e intentar restablecer la relación amorosa que, tres años atrás, había mantenido con la Novia.

El orden al que se enfrenta Leonardo -desde una tendencia en absoluto política, sino meramente sentimental- es el que impide el desarrollo de su individualidad. La configuración del yo es inviable en los espacios rurales donde la maledicencia y la murmuración, la asfixia de los espacios abiertos, impiden que el sujeto se comporte en tanto que individuo. Todos están sometidos al juicio público y por ello resulta imprescindible mantener las apariencias. Sin embargo, la imposibilidad del yo no viene únicamente determinada desde el humus ideológico supraestructural, sino también desde los mecanismos de producción capitalistas que convierten a los sujetos en mercancías. Porque el yo, una vez se ha configurado plenamente, no puede sino introducirse en las relaciones de mercado y convertirse en capital vendible. Así funciona el matrimonio burgués. La finalidad de la boda entre la Novia y el Novio es que «se van a juntar dos buenos capitales» (García Lorca, 2005: 105). ${ }^{3}$ Y esto se constata con la conversación que mantienen el Padre y la Madre en el cuadro tercero del primer acto:

PADRE (sonriendo). Tú eres más rica que yo. Las viñas valen un capital. Cada pámpano una moneda de plata. Lo que siento es que las tierras ... ¿entiendes? ... estén separadas. A mí me gusta todo junto. Una espina tengo en el corazón, y es la huertecilla ésa metida entre mis tierras, que no me quieren vender por todo el oro del mundo [...] Lo mío es de ella y lo tuyo es de él. Por eso. Para verlo todo junto, ¡que junto es una hermosura! (García Lorca, 2005: 110).

El matrimonio, efectivamente, encuentra su motivo en la unión de tierras. La forma de la familia, por lo tanto, no se basa «en condiciones naturales, sino económicas» (Engels, 1970: 83). Las condiciones sobre las que se funda el matrimonio burgués representan, según Engels, «el triunfo de la propiedad privada sobre la propiedad común primitiva, ori-

\footnotetext{
3 Josephs y Caballero anotan en su edición de Cátedra que los dineros y los buenos capitales a los que hacen referencia tienen que ser relativos. Apuntan los críticos en una nota a pie de texto: «Estos campesinos no son muy ricos; tienen que luchar duramente con su medio ambiente que es la tierra». Ciertamente, según las descripciones de la obra, bien parece que no se trata de una alta burguesía terrateniente, sino de la clase pequeño-burguesa que ocupa ese espacio intermedio de la circulación del capital y que posee los medios de producción a la vez que los explota. En la obra hay una referencia clara a esta situación, cuando el padre afirma que es necesario que se tengan muchos hijos porque la tierra necesita brazos no asalariados (lo cual indica que el poder económico de la familia no debía de ser desorbitado). Dice así el texto:

PADRE. Yo quiero que tengan muchos [hijos]. Esta tierra necesita brazos que no sean pagados. [...] Y estos brazos tienen que ser de los dueños, que castiguen y que dominen, que hagan brotar las simientes. Se necesitan muchos hijos (García Lorca, 2005: 132).

El sistema de explotación neo-feudal remite al tiempo histórico en que todavía no se ha producido la disociación entre los medios de producción y productor inmediato, lo cual atestigua el atraso que vivía el campo andaluz.
} 
ginada espontáneamente» (Engels, 1970: 83). Es decir, como habían dicho Marx y Engels en el Manifiesto comunista: «la burguesía ha desgarrado el velo de emocionante sentimentalismo que encubría las relaciones familiares y las ha reducido a simples relaciones de dinero» (Marx-Engels, 1998: 19) ${ }^{4}$.

El único inconveniente es que no todo va a salir según lo previsto: el hecho de que las tierras no se junten, de forma física, por medio del matrimonio, no puede ser sino un signo de alerta que advierte sobre la imposibilidad de la unión. Todo el oro del mundo no es suficiente para realizar el propósito, porque un individuo -que el lector/espectador desconoce- no quiere (no es su voluntad) vender las tierras, como tampoco podrán juntarse el Novio y la Novia, porque por medio aparecerá en escena otro individuo igualmente dispuesto a luchar por lo que quiere. La voluntad desestabiliza el orden social hegemónico.

El mundo cerrado y perfecto que representa la zona rural andaluza, bajo el dominio supraestructural de la pequeña burguesía, empieza a agrietarse a medida que se desarrolla el capitalismo industrial y las categorías segregadas de su matriz ideológica empiezan a hacer mella en el mundo rural. Es resultado de las relaciones sociales del capitalismo, insistimos, la noción de individualidad, pero también lo es la alienación y la fragmentación del nuevo sujeto «libre». En el segundo diálogo de la obra, entre la Madre y la Vecina, vuelve a aparecer otro individuo con nombre propio, Rafael, sobre cuya situación entablan conversación los personajes de la escena. Rafael, inserto en las relaciones de producción capitalistas, es un obrero de la industria que ha intercambiado libremente su fuerza de trabajo por un salario. Dos días antes de la conversación, regresó a casa con los dos brazos amputados a causa de un accidente laboral. Así lo cuenta la Vecina: «Hace dos días trajeron al hijo de mi vecina con los dos brazos cortados por la máquina» (García Lorca, 2005: 98). La fragmentación del individuo moderno - a consecuencia de la alienación- no se encuentra realizada únicamente en los procesos productivos capitalistas, sino también materializadas en el propio cuerpo.

Del mismo modo, el mundo rural está sufriendo la degradación de los valores del honor y la valentía, con la introducción de instrumentos como la pistola y la navaja. No hay posibilidad de respetar los códigos cuando una «cosa pequeña como una pistola o una navaja pueda acabar con un hombre que es un toro» (García Lorca, 2005: 98), afirma la Madre. No es lugar para valientes donde existan navajas y pistolas, apéndices de cobardes. Y añadirá la Madre más adelante, ratificando su obsesión por las navajas tras haber perdido a marido e hijo en sendas reyertas, haciendo referencia a su hijo muerto: $\ll_{i}$ Veintidós años! Esa edad tendría mi hijo mayor si viviera. Que viviría caliente y macho como era, si los hombres no hubieran inventado las navajas» (García Lorca, 2005: 111). El tiempo subjuntivo de las palabras de la Madre hacen referencia, directamente, a lo que tendría que haber sido, que dista sustancialmente de lo que finalmente es. Porque el tener que ser, del orden natural de la ideología pequeño-burguesa, queda alterado por el querer ser de la epistemología capitalista. La alteración del orden remite al caos en la mentalidad pequeñoburguesa, es un signo evidente de la presencia del peligro constante y la desprotección, que representan los espacios abiertos:

\footnotetext{
4 También el personaje de la Madre confiesa que el día de su boda fue «como una herencia» (García Lorca, 2005: 138). Del mismo modo, Leonardo no puede casarse con la Novia, en la prehistoria de la obra, por motivos puramente económicos. Así se lo reprochará Leonardo a la Novia en el cuadro primero del acto segundo: «¿Qué he sido yo para ti? Abre y refresca tu recuerdo. Pero dos bueyes y una mala choza son casi nada. Ésa es la espina» (García Lorca, 2005: 119). Ciertamente, el valor de Leonardo se calcula por sus escasas posesiones.
} 
MADRE. No... Si hablo es porque... ¿Cómo no voy a hablar viéndote salir por esa puerta? Es que no me gusta que lleves navaja. Es que... que no quisiera que salieras al campo.

NOVIO (riendo). ¡Vamos!

MADRE. Que me gustaría que fueras una mujer. No te irías al arroyo ahora y bordaríamos las dos cenefas y perritos de lana (García Lorca, 2005: 95).

La mujer, recluida en casa, encuentra la protección necesaria. Pero no porque dentro de ella encuentre la libertad, en tanto que noción burguesa vinculada a los espacios propios, sino porque dentro de ella conserva la honra y la integridad moral. La mujer nunca puede configurar su identidad porque el código establecido las postraba en casa, reproduciendo con idéntica mecánica las labores domésticas y sirviendo al cuidado de los hijos, sin trascender su condición de animal. La mujer aparece oprimida en el propio yugo familiar. Como indicaba Friedrich Engels en El origen de la familia, de la propiedad privada y del Estado:

El primer antagonismo de clases que apareció en la historia coincide con el desarrollo del antagonismo entre el hombre y la mujer en la monogamia; y la primera opresión de clases, con la del sexo femenino por el masculino.

\section{A esto cabe añadir que}

[...] si la mujer cumple con sus deberes en el servicio privado de la familia, queda excluida del trabajo social y no puede ganar nada; y si quiere tomar parte en la gran industria social y ganar por su cuenta, le es imposible cumplir con los deberes de la familia. [...]. La familia individual moderna se funda en la esclavitud doméstica franca o más o menos disimulada de la mujer, y la sociedad moderna es una masa cuyas moléculas son las familias individuales.

Sobre este aspecto, Fernández Cifuentes señalará, a partir de Bodas de sangre, una disyuntiva constante en la obra de García Lorca: la oposición entre lo masculino y lo femenino:

Por una parte, los parlamentos de Bodas de sangre incluyen ciertas peticiones de principio sobre la diferencia de géneros, una especie de categorías absolutas que sacrifican toda duda o ambición de la conciencia individual: «los hombres, hombres; el trigo, trigo»; «Una mujer con un hombre, y ya está»; el matrimonio significa para la mujer «un hombre, unos hijos y una pared de dos varas de ancho para todo lo demás»; «iLos varones son del viento! Tienen por fuerza que manejar armas. Las niñas no salen jamás a la calle» (Fernández Cifuentes, 1986: 148).

La función social entre hombre y mujer es evidente: el hombre está destinado al trabajo y a la guerra (trigo y armas), mientras que la mujer debe servir para el matrimonio y para cuidar de la casa. La mujer, cuya función queda relegada a la casa, donde le es ajena todo transformación social, no puede sino convertirse en un sujeto conductor de la ideología dominante, que representa la Madre de Bodas de sangre o de forma más significativa Bernarda Alba. De este modo, el teatro de Lorca nos presenta, en palabras de José Alberich, 
[...] a la mujer como ser social, sus prejuicios conservadores, su orgullo de clase, su intransigencia moral, su sentido de la familia, etc. A este nivel se encuentra el mensaje social, transformador, de su teatro, tan importante y tan poco comprendido en España (Alberich, 1960: 592).

Lorca nos muestra el código en que la mujer queda desterrada de la vida social, pero como añade Luis Fernández Cifuentes seguidamente: «la misma enunciación del código es una advertencia, un indicio de su inmediata trasgresión: la Novia se reparte entre dos hombres, abandona la casa y genera así la anunciada tragedia» (Fernández Cifuentes, 1986: 148). Porque, efectivamente, otra imagen de la mujer traerá Lorca en su teatro, la que se sitúa «en el subsuelo de la feminidad, en la caverna de su erotismo, al nivel, en parte cons-ciente, en parte subconsciente, desde donde se rigen sus amores y sus odios» (Alberich, 1960: 583). Cuando la Novia tome conciencia de su individualidad y salga a los espacios abiertos -contrariando la opinión de la Madre de que las mujeres no salen al campo-, entonces se desencadenará la tragedia, por medio de la fuga. El inconsciente ideológico de la libertad de la Novia coincidirá con su inconsciente libidinal, al reconocer que su huida es fruto de sus pulsiones sexuales, su libertad como síntoma del deseo incontrolable. Así se lo hace saber la Novia a Leonardo:

NOVIA.

¡Ay qué sinrazón! No quiero

Contigo cama ni cena

y no hay minuto del día

que estar contigo no quiera (García Lorca, 2005: 152).

Efectivamente con él no puede perpetuar los códigos dominantes: la cama -el tálamo como símbolo de unión matrimonial y económica- y la cena -como símbolo de la opresión que el hombre ejerce sobre la mujer como materialización de su sirvienta doméstica. Pero elige la huida porque no puede soportar la ausencia de Leonardo. Su voluntad, su libertad, su deseo, se enfrenta al orden dominante y por ello ha hecho lo que reconoce con sus propias palabras:

He dejado a un hombre duro

y a toda su descendencia

en la mitad de la boda

y con la corona puesta (García Lorca, 2005: 152).

Sin embargo, resulta imprescindible anotar que la Novia, tras fugarse con Leonardo, ratificando su individualidad y reivindicando «el instante pleno frente al futuro artificial que se le promete» (Rodríguez, 1994: 77), vuelve a la lógica de la sumisión indicando, primero, que Leonardo se la ha llevado a la fuerza, por medio del siguiente diálogo dramático:

\section{LEONARDO.}

Ya dimos el paso, ¡calla!

porque nos persiguen cerca

$\mathrm{y}$ te he de llevar conmigo. 
NOVIA.

¡Pero ha de ser a la fuerza!

LEONARDO.

¿A la fuerza? ¿Quién bajó

primero las escaleras?

NOVIA.

Yo las bajé.

LEONARDO.

¿Quién le puso

al caballo bridas nuevas?

NOVIA.

Yo misma. Verdad.

LEONARDO.

¿Y qué manos

NOVIA me calzaron las espuelas?

Estas manos, que son tuyas [...] (García Lorca, 2005: 150-151).

Su individualidad ha llevado a la Novia a fugarse con Leonardo, sin embargo, una vez la fuga se ha realizado, reniega de su nueva identidad e intenta convencerse de que ha sido raptada. Sólo cuando las palabras de Leonardo evidencien que ha huido por su propia voluntad, entonces se entrega a él. Pero -es importante insistir en esto- se entrega aceptando su sumisión. Aunque el comportamiento de la Novia pueda caracterizarse de subversivo -en efecto se enfrenta al orden dominante-, en estricto no podemos hablar de emancipación de la mujer puesto que, a la vez que se libera de la figura de su madre, se somete a la del amante. Lo corroboran las palabras que emite momentos antes de acostarse con Leonardo, donde no sólo se somete al hombre sino que a él se humilla:

NOVIA.

Y yo dormiré a tus pies

para guardar lo que sueñas.

Desnuda, mirando al campo,

(Dramática)

como si fuera una perra,

¡porque lo soy! [...] (García Lorca, 2005: 153).

Claro que el hecho de rebajarse e identificarse con una perra no es sino causa de la pérdida de la honra que ha supuesto la fuga en un acontecimiento tan popular y que atrae las miradas de todo el pueblo como es una boda. Por eso le pide, aunque con sarcasmo, lo que sigue:

Llévame de feria en feria,

Dolor de mujer honrada,

A que las gentes me vean

Con las sábanas de boda

Al aire, como banderas (García Lorca, 2005: 153).

La individualidad entra en conflicto con los valores supraestructurales como es la honra. El espacio público aparece constantemente corrompido por las murmuraciones y 
el qué dirán. La palabra anuncia el desorden. En las conversaciones en las que participa la Madre hay una referencia constante a la falta de transparencia de la Novia, cuyo pasado amoroso parece manchar su honra. La Madre lo sospecha y se lo pregunta al Novio que responde con más indiferencia que certidumbre (García Lorca, 2005: 96). ${ }^{5}$ Pero el rumor popular deja entrever que efectivamente mantuvo un romance con Leonardo:

MADRE. [...] A mí me habían dicho que la muchacha tuvo un novio hace tiempo.

VECINA. Tendría ella quince años. Él se casó ya hace dos, con una prima de ella, por cierto. Nadie se acuerda del noviazgo.

MADRE. ¿Cómo te acuerdas tú?

VECINA. ¡Me haces unas preguntas!

MADRE. A cada una le gusta enterarse de lo que le duele. ¿Quién fue el novio?

VECINA. Leonardo.

MADRE. ¿Qué Leonardo?

VECINA. Leonardo el de los Félix.

MADRE (levantándose). ¡De los Félix!

VECINA. Mujer, ¿qué culpa tiene Leonardo de nada? Él tenía ocho años cuando las cuestiones.

Por medio de la palabra la Madre llega a conocer que la Novia no sólo había tenido un novio en el pasado, sino que éste era Leonardo, cuya familia, la de los Félix, merece su odio por considerarla el origen de su sino.

Fernández Cifuentes señala que «hablar, decir, son instrumentos de fatalidad, cómplices de la transgresión y de la muerte: la Madre quisiera que la Novia y su madre "fueran como dos cardos, que ninguna persona los nombre"» (Fernández Cifuentes, 1986: 153). Un parlamento parecido emite la Madre ante el Novio al afirmar:

MADRE. No lo sé yo misma. Así, de pronto, siempre me sorprende. Yo sé que la muchacha es buena. ¿Verdad que sí? Modosa. Trabajadora. Amansa su pan y cose sus faldas, y siento, sin embargo, cuando la nombro, como si me dieran una pedrada en la frente (García Lorca, 2005: 95-96).

Nombrar, dar nombre, significa a su vez otorgarle identidad (libertad, por lo tanto) a un sujeto. Es preciso no nombrar si no se quiere desestabilizar el orden social con el golpe de una pedrada. Fernández Cifuentes, en referencia a La casa de Bernarda Alba, dice algo que es muy pertinente señalar aquí:

...las palabras, en lugar de transmitir los hechos, se vuelven contra ellos, los traicionan, los alejan; se reducen los significantes y se multiplican los significados, de manera que palabras y gestos llegan cargados de connotaciones inciertas; las historias ajenas contadas en el escenario son fundamentalmente borrosos espejos de las que ocurren en aquellos interiores de la casa de Bernarda donde el espectador no tiene acceso; el diálogo es siempre truncado e incompleto (Fernández Cifuentes, 1986: 195-196).

5 El diálogo es escueto:

MADRE. [...] ¿Ella tuvo novio, no?

NOVIO. No sé. Creo que no. 
En oposición a la palabra, surge el silencio que «comporta, en cambio, garantías de continuidad e incluso de felicidad» (Fernández Cifuentes, 1986: 154). El autor de estas palabras cita a continuación, para ejemplificar el caso, lo dicho por la Vecina: «No te opongas a la felicidad de tu hijo. No le digas nada. Tú estás vieja. Yo también. A ti y a mí nos toca callar» (García Lorca, 2005: 100). Hay que censurar la palabra y aceptar el desarrollo de lo acontecido en silencio. Las palabras, tergiversadas por medio de rumores y murmuraciones, perturban la templanza social, cuestionando la decencia, honra y bondad de sus personajes.

Es un aspecto común en el teatro de Lorca: la presencia del espacio público, donde domina la palabra en forma de maledicencia, como instrumento que impide el desarrollo de la individualidad. Los personajes lorquianos, en efecto, son definidos por las palabras -juicios y prejucios- que los demás personajes emiten sobre ellos. Los personajes nunca pueden definirse, darse nombre, por sí mismos, sino que será lo externo quien les dará el nombre. En el teatro de Lorca -y en concreto en Bodas de sangre- lo público funcionará siempre como una negación de la libertad. También en La casa de Bernarda Alba este mecanismo se pone en funcionamiento, aunque a primera vista parezca que el único aparato coercitivo es el ejercido por Bernarda dentro de la propia casa. Dennis A. Klein analiza La casa de Bernarda Alba según unos parámetros de asociación entre dentro/fuera y represión/libertad:

Si el interior representa la represión, la sociedad de fuera representa la libertad. Son los muros que separan la decencia de la inmoralidad: a las mujeres de los hombres, el encarcelamiento de la libertad, la frustración de la sexualidad. La separación entre dentro y fuera es tan compleja como el poder de Bernarda lo permite (Klein, 1986: 287-288).

No obstante, si bien es cierto que el interior representa la represión encarnizada de Bernarda, lo exterior es el lugar desde donde emerge la ideología del orden y de la moralidad. La autoridad de Bernarda no es sino una reproducción en el interior de su casa de lo que está establecido en la sociedad de fuera. Las hijas de Bernarda no carecen de libertad a causa de un desarreglo en la psique de su madre, sino que es una cuestión ideológica, una reacción ante la individualización que no puede sino conducir al desorden, al caos. Luis García Montero, en un artículo muy acertado sobre La casa de Bernarda Alba, da con la clave:

Objetivamente, la sucesión de hechos en La casa de Bernarda Alba denuncia la no existencia de un lugar oculto para el poder en cualquier sociedad estructurada por la separación entre lo privado y lo público, porque esa distancia imaginaria tiene como única consecuencia posible la identificación absoluta con el orden (García Montero, 1986: 367).

He aquí la problemática del yo, de la individualización, que en su enfrentamiento con la ideología dominante produce la tragedia. La sociedad rural andaluza, decíamos arriba, facilitó a Lorca la composición formal de la tragedia, sin embargo el espacio andaluz era insuficiente y por ello resultaba necesaria la aparición de la ideología de la individualidad. Las palabras de García-Posada sin duda aportarán claridad a este asunto:

La realidad rural es la de una tierra implacablemente castigada por el sol, cuya correlación es la Andalucía penibética, los campos de Najar; una tierra maldita. El valor dominante de la pequeña burguesía campesina son las tierras, el dinero. El afán por el dominio engendra fuertes rivalidades. Las hay entre la Madre y la familia de los Félix, y se prolonga a 
través del tiempo, en la mujer tradición trágica. Culto a de la tierra, y del odio y la muerte. Queda un tercer culto: el del sexo, un sexo fálico. Pero no del sexo como gratuidad, sino como generación, fertilidad (García-Posada, 1980: 599).

El deseo, el sexo, las pulsiones libidinales -todo ello segregación de la individualidad- en su fricción con la ideología dominante desencadenará la tragedia moderna: «El entramado social de los valores salta hecho pedazos por la fuerza tumultuosa del deseo, que aquél había tratado en vano de contener y reprimir» (García-Posada, 1980: 599). El deseo trastoca el orden social que da origen a la tragedia, pero lo más relevante, en cuanto a la forma, en esta obra de Lorca es que el deseo no sólo rompe el orden social sino también el orden «racional» o narrativo. Hasta el momento de la fuga, Bodas de sangre se cons-truye desde unos parámetros que podemos denominar, sin riesgo alguno, de realistas. De hecho, es de sobra sabido, que Lorca parte de un hecho real, aparecido en la prensa de la época, para componer esta tragedia. Así lo explica Mario Hernández en la introducción a su edición de la obra:

El 25 de junio de 1928 la prensa española recogía un suceso acaecido en Najar, un pueblo de la provincia de Almería en el extremo e inhóspito sureste de España. Marcelle Auclair ha relatado, siguiendo los recuerdos de Santiago Ontañón, la sorpresa de García Lorca al leer la historia en el diario $A B C$. Su comentario inmediato fue que allí había «un drama difícil de inventar». Sobre esta base surgiría Bodas de sangre (Hernández, 2007: 24).

El realismo (o la autenticidad) inicial se trunca a la vez que se rompe el orden social. El plano social, campesino y rural, queda interrumpido ahora por una naturaleza fuertemente poética, entrando en escena la Mendiga y la Luna, como una doble alegoría de la Muerte. Como señala García-Posada, «con la quiebra del mundo social se produce también la del realismo que hasta ese momento preside la tragedia, para dar paso -dice el autora la fantasía poética» (García-Posada, 1980: 599).

De este modo se construye la tragedia moderna, en contenido y forma, con la quiebra del orden por medio del yo. Sin embargo la reivindicación de la individualidad, del espacio propio, de la libertad de elección y de deseo, supone siempre la muerte. La tragedia moderna, inscrita en la problemática del yo, de Federico García Lorca -y en concreto en Bodas de sangre-supone una imposibilidad (inexistencia o negación) del ejercicio de la libertad. Pero el acierto de Lorca es que no sitúa esta carencia histórica en el marco de la tragedia clásica, donde el héroe tiene que morir de forma inexorable, porque es éste su sino; por el contrario, Bodas de sangre postula la negación de la libertad desde la imposibilidad de nombrarse. Es decir, no como un mal endémico, irreparable e inmanente al hombre, sino como una consecuencia histórica en un tiempo y espacio concretos. Podríamos concluir, trayendo de nuevo las palabras de Luis García Montero citadas arriba, que Bodas de sangre es una denuncia por la inexistencia de un espacio propio donde poder realizarse una identidad propia, un nombre, una individualidad: el yo. Pero difícilmente podemos aceptar, dentro de la lógica del teatro de García Lorca, la noción de denuncia para definir sus obras, ya que como señalaba Lázaro Carreter: «en Federico hay una ancha veta liberal, pero su arte no está comprometido, no es el arte de una facción; mucho menos el acta de acusación y procesamiento levantada en nombre de unos contra los demás» (Lázaro Carreter, 1984: 584). En efecto, García Lorca, por medio del desenlace trágico, evita traer al texto una solución histórica, una síntesis definitiva. Pero como afirmaba Engels no es ésta la obligación del poeta, sino únicamente presentar el conflicto. Éstas son sus palabras: 
Pero yo creo que la tendencia debe resaltar de la acción y de la situación, sin que sea explícitamente formulada, y el poeta no está obligado a dar al lector la solución histórica futura de los conflictos que describe [...] En mi opinión, una novela de tendencia socialista llena perfectamente su tarea cuando, por una pintura fiel de las relaciones reales, destruye las ilusiones convencionales, rompe el optimismo del mundo burgués, constriñe a dudar de la perennidad del orden existente, aunque el autor no indique directamente la solución, aunque, dado el caso, no tome ostensiblemente partido (Marx-Engels, 1964: 178).

Sin embargo, la falta de síntesis, el hecho de que la libertad conduzca irremediablemente a la muerte, puede ser interpretado como un sistema de alerta que contribuya de igual modo al mantenimiento del orden y a la transmisión de ideología. En esta línea, en la detección de rasgos reaccionarios en la obra de Federico García Lorca, está investigando actualmente el profesor de la Universidad de Granada José Antonio Fortes, mostrando los ideologemas que posteriormente contribuirían a la construcción ideológica del fascismo. Es el caso del vacío ideológico de la literatura previa a la Guerra Civil española:

Ese vacío (ideológico): no hay agitaciones campesinas en Andalucía ni en España, donde no hay tampoco agitaciones proletarias, sino la pax burguesa. Ese vacío (ideológico), sobre la realidad histórico material: ni proletarios ni campesinos revolucionarios, sino buenos hombres, sino el buen salvaje, el pueblo honrado, el pueblo trabajador, cantado a base de símbolos y de metáforas, de imágenes y mil formas de lenguaje sublime elaborado por las vanguardias. En discursos que cruzan el intelectualismo del espíritu con el populismo (Fortes, 2005).

\section{Y, en concreto, en la literatura de García Lorca:}

el espíritu del pueblo español que anida allí donde se abre la desconcienciación de clase, el aideologismo, aclasismo y servilismo de clase, permite la exultación de los valores y principios fundamentales que la ideología fascista, que el fascismo y solo, solo el fascismo organiza, propugna, defiende y eleva a categoría del espíritu del pueblo español. García Lorca exalta: la ideología de la madre, la ideología de la sangre, la ideología de la tierra, la ideología del alma del pueblo, la ideología de la raza, la ideología de la familia, la ideología patriarcal autoritaria, la ideología de la jerarquía social natural, la ideología de la sexualidad reproductora, la ideología del matrimonio, la ideología tradicionalista, la ideología liberticida, la ideología de la inhibición sublimadora, la ideología del irracionalismo, la ideología de la violencia, la ideología de la fuerza, y cuantas demás estrategias e ideologías subsidiarias a cuya sombra y fantasmagoría se pudieran desarrollar, como por ejemplo a la sombra y fantasmagoría de la ideología de la Norma y el Estilo, de la ideología de la dialéctica de los puños y las pistolas, de la ideología de la Cruzada de Salvación, etc. (Fortes, 2005).

En efecto, el carácter reaccionario parece estar latente en la producción literaria de entreguerras. ${ }^{6}$ Sin embargo, una cosa es considerar que esta literatura es el resultado de las contradicciones históricas en que se inscriben y otra, bien distinta, que contribuyan, de forma explícita, a la constitución de la posterior ideología del fascismo nacional. Pero éste es ya otro tema.

6 De hecho, he tratado en otro artículo (Becerra Mayor, 2007: 211-226) el fenómeno de la vanguardia como una producción de la pequeña-burguesía que se enfrenta a la infraestructura del capitalismo que se está empezando a 


\section{BIBLIOGRAFÍA}

Alberich, J. (1960): «El erotismo femenino en el teatro de García Loca». En: Papeles de Son Armadans, 39, 9-36. En: Historia y crítica de la literatura española, VII, 1984. Barcelona: Crítica.

Bajtín, M. (1989): «Épica y novela (acerca de la metodología del análisis novelístico)». En: Teoría y estética de la novela. Madrid: Taurus, 449-485.

Becerra Mayor, D. (2007): «Fascismo y vanguardia. Introducción a la producción ideológica de la pequeña burguesía». En: Verba hispánica, 15/a, 211-226.

Clair, J. (2000): La responsabilidad del artista. Madrid: Visor.

Engels, F. (1970): El origen de la familia, de la propiedad privada y del Estado. Madrid: Fundamentos.

Fernández Cifuentes L. (1986): García Lorca en el Teatro: la norma y la diferencia. Zaragoza: Universidad de Zaragoza.

Fortes, J. A. (2005): «Populismo y literatura». En: La jiribilla, 3, 194. En: www.lajiribilla.cu/ 2005/n194_01/194_20.html.

García Lorca, F. (2005): Bodas de sangre. Madrid: Cátedra.

García Montero, L. (1986): «El teatro, la casa y Bernarda Alba». En: Cuadernos hispanoamericanos, (Homenaje a García Lorca), 433-434, 359-270.

García-Posada, M. (1980): Introducción a Federico García Lorca, Obras, I: Teatro. Barcelona: Akal, 64-73. En: Historia y crítica de la literatura española, VII, 1984. Barcelona: Crítica.

Hernández, M. (2007): Introducción a Bodas de sangre. Madrid: Alianza, 7-60.

Jameson, F. (2008): Fables of Aggression: Wyndham Lewis, the Modernist as Fascist. London/New York: Verso.

Josephs, A., Caballero, J. (2005): Introducción a Bodas de sangre. Madrid: Cátedra, 11-90.

Klein, D. A. (1986): «Las sociedades creadas en el teatro de Federico García Lorca». En: Cuadernos hispanoamericanos (Homenaje a García Lorca), 433-434, 284-292.

Lázaro Carreter, F. (1960): «Apuntes sobre el teatro de García Lorca» En: Papeles de Son Armadans, 52. Reeditado en: Gil, Ildefonso-Manuel (1975): Federico García Lorca. Madrid: Taurus, 327-342. En: Historia y crítica de la literatura española, VII, 1984. Barcelona: Crítica.

Lukács, G. (1970): «Las civilizaciones cerradas» y «Epopeya y novela». En: Teoría de la novela. Barcelona: Siglo XX, 29-39, 59-72.

Marx, K., Engels, F. (1964): Sobre arte y literatura. Buenos Aires: Revival.

Marx, K., Engels, F. (1998): Manifiesto comunista. Madrid: Debate.

Ortega, J. (1989): Conciencia estética y social en la obra de García Lorca. Granada: Universidad de Granada.

Rodríguez, J. C. (1994): Lorca y el sentido. Un inconsciente para una historia. Madrid: Akal.

Rodríguez, J. C. (2002): De qué hablamos cuando hablamos de literatura. Granada: Comares.

consolidar en el periodo de entreguerras, como un producto que es el resultado de las mismas luchas ideológicas que el fascismo. Vid., igualmente, Jameson (2008). El ensayo de Jameson pone en relación el rechazo de la realidad histórica y su sustitución con la expresión desmesurada con el rechazo del fascismo de la realidad histórica y por sus soluciones políticas puramente formalistas. Vid., también, Jean CLAIR, La responsabilidad del artista, Madrid, Visor, 2000; se trata de un ensayo que, con peor suerte y desde unos postulados distintos a los dos anterio-res, pone en relación los totalitarismos políticos -incluido el soviético- con la persecución de una forma estética total de las vanguardias. 
Članek skuša umestiti delo Federica Garcíe Lorce, še posebej njegovo tragedijo Krvava svatba, ki se dogaja na podeželju, v specifičen zgodovinski okvir. Medvojno literarno ustvarjanje je opredeljeno $\mathrm{z}$ razrednim nasprotjem med malo buržoazijo, ki obvladuje ideološko nadgradnjo oziroma superstrukturo, in industrijsko, urbano buržuazijo, ki skuša zagotoviti konsolidacijo kapitalizma z gospodarskim razvojem baze. Reakcija nadgradnje, ki prepreči pojav novih vrednot, kot sta želja in individualnost, ki vznikneta iz buržoazne ideologije, povzroči rojstvo moderne tragedije ali problematike jaza. Tragedija ni več latenca smrti, pač pa nezmožnost poimenovanja ali individualiziranja. 